\title{
Teachers' use of language in multilingual mathematics classrooms during trouble-spots
}

\author{
Rabih El Mouhayar, American University of Beirut (Lebanon)
}

Teachers' use of language in multilingual mathematics classrooms during trouble-spots

\section{Abstract}

Mathematics teaching in a foreign language may lead to discrimination for some learners specifically during trouble-spots that require the construction of shared-understanding. This research compares teacher-learner interaction in two classrooms of Lebanon where mathematics is taught in a foreign language. Eighteen lessons were recorded and transcribed, and utterances of teacher and learners were coded at the levels of: school; session; interlocutor; language use; move and function. Quantitative analysis of language use and qualitative illustrations of representative sequences are reported. The triadic dialogue as the dominant mode of interaction and the multilingual nature of language were found unique aspects of classroom teacher talk. Differences in the roles of language as a resource for meaning-making were also identified. Findings are discussed within sociocultural and ethnomethodological views of language as a medium to achieve mathematics teaching and learning.

Keywords. Teacher-learner interaction; classroom teacher talk; trouble-spot; language; multilingual classrooms.

La lengua en uso de profesores en aulas de matemáticas multilingües durante focos de tensión

\section{Resumen}

La enseñanza de matemáticas en una lengua extranjera puede conducir a la discriminación de algunos alumnos particularmente durante focos de tensión que requieren de la construcción de comprensión compartida. Esta investigación compara la interacción profesor-alumno en dos aulas del Líbano donde las matemáticas se enseñan en una lengua extranjera. Se grabaron y transcribieron diechiocho sesiones de clase, y las intervenciones de profesor y alumnos se codificaron a nivel de: escuela; sesión; interlocutor; uso de la lengua; movimiento y función. Aquí se documentan el análisis cuantitativo del uso de la lengua e ilustraciones de secuencias representativas. El diálogo triádico como modo dominante de interacción y la naturaleza multilingüe de la lenga aparecieron como aspectos únicos del habla del profesor en clase. También se detectaron diferencias en el papel de la lengua como recurso para producir significado. Los resultados se discuten con visiones socioculturales y etnometodológicas de la lengua como medio para lograr enseñar y aprender matemáticas.

Palabras clave. Interacción alumno-profesor; habla del profesor en clase; foco de tensión. lengua; aula multilingüe.

\section{Introduction}

Classroom teacher talk and the ways in which different languages (e.g. colloquial, foreign) are used within multilingual classroom environments are fundamental for supporting meaningful mathematics teaching and learning (Adler 1999; Khisty \& Chval, 2002). From this perspective, research in mathematics education needs to study classroom teacher talk and language practices in multilingual classrooms and their impact on teaching and learning; particularly, for learners from low or middle socioeconomic status. These learners frequently face a linguistic discrimination by which lack of proficiency in the foreign language, used as the language of instruction, may be a factor contributing to poor accomplishment in learning mathematics. 
The current research addresses multilingual classrooms in Lebanon, a Middle Eastern country, in which private precollege education serves almost $60 \%$ of K-12 students whereas public school system provides almost tuition free education to $40 \%$ of students. In Lebanon, mathematics and science are taught in a foreign language based on a policy that was established in 1926 during the French Mandate. While very few schools use Arabic as language of instruction to teach mathematics and science at the elementary school cycle (grades 1-6), a foreign language (English or French) is used as a language of instruction for teaching mathematics and science in the public and private sectors. Teachers and students in Lebanon are multilinguals with Lebanese colloquial Arabic as their native spoken language, Arabic standard language as their language of literacy and English or French, as the language of instruction for mathematics and science. The feature of multilingualism in mathematics and science classrooms in Lebanon is not only given by using a foreign language but also given by two varieties of Arabic language, standard Arabic and colloquial Arabic. All these languages 'come together' for mathematics and science education in a unique way.

I explore the effects of using Lebanese spoken colloquial Arabic as a resource for meaning-making during 'trouble-spots' (Alibali et al., 2013) when learners commit errors, hesitate or have no shared understanding with the teacher. In particular, I explore regularities in classroom talk when learners begin to encounter algebra in grade seven. I examine whether various regularities in the use of home language, in this case colloquial Arabic, and language of instruction impact on the pedagogical quality of classroom teacher talk during trouble-spots. To this end, I compare and contrast classroom teacher talk in two grade seven classrooms in a public and a private school. I draw on sociocultural and ethnomethodological approaches in mathematics education. Adopting both theoretical approaches allows me to conceptualize language as a medium to achieve mathematics teaching and learning in classroom interaction and to consider the role of language as a resource for meaning-making.

\section{Theoretical approaches to analyze language use in classroom interaction}

In recent investigations, a combination of theories from various disciplines has framed research in mathematics education to explore relationships between language, classroom interaction and learning. The current study uses sociocultural and ethnomethological approaches to analyze language use in multilingual classroom interaction. Classrooms, as social contexts, are usually framed within a sociocultural theory of learning with a focus on the role of language in mathematics teaching and learning. The principles of this theory originate in Vygotsky's $(1978,1986)$ sociocultural theory, which focuses on symbolic tools (e.g. language) as media of communication and reasoning. Ethnomethodology has also been used in mathematics education. The foundations of this theory were developed by Garfinkel (1967). Based on this theory, research in mathematics education focuses on how language is used as a medium to achieve mathematics teaching and learning in classroom interaction instead of focusing on the language per se. Ingram (2018) argues that ethnomethodology allows thoroughness to analyze classroom interaction since it "is both a theoretical perspective on social actions and a method for researching these actions" (p. 1065). Here, interaction becomes the unit of analysis by focusing on what the teacher and/or students "are doing with their utterances or gestures in this interaction" (p. 1065). The focus becomes on what those interlocutors utter and how they state their utterances, and hence it allows for the examination of classroom interaction complexity and the focusing on characterizing structures and regularities of interaction. 
Paying attention to the specifics of classroom teacher talk reveals variations within broader discourse regularities thus permitting for further consideration of quality of education. Within this perspective, research in education relates interaction to the type of discourse in classroom teacher talk, and consequently its impact on quality of teaching and learning. For instance, research distinguishes between univocal and dialogic discourse in classroom teacher talk. Univocal discourse occurs when classroom interaction focuses only on producing a form of communication in which the student receives the "exact" message that the teacher expects to be received. In contrast, dialogic discourse is manifested when classroom interaction involves dialogue as a process for reasoning (Wertsch, 1991). The concept of dialogicity is based on Bakhtin's (1981) theory of language, which perceives language as dialogic. El Mouhayar (2020a) and Salloum and BouJaoude (2019) suggest that univocal discourse hinders conceptual understanding, whereas dialogic discourse supports it.

Another example of regularities in classroom interaction is the triadic dialogue. This turn taking structure follows initiation-response-follow-up moves. It was first outlined by Sinclair and Coulthard (1975) and then various studies in mathematics and science education explored this pattern in different countries (e.g. Amin \& Badreddine, 2020; El Mouhayar, 2019, 2020a, 2020b, 2021; Lemke, 1990). Acknowledging the versatile nature of triadic dialogue, El Mouhayar (2020a) shows how this mode has been utilized by a teacher in a Lebanese multilingual mathematics classroom, where English is the language of instruction, to manage shifts between pre-algebraic and algebraic generalization levels of reasoning and among knowledge types. Dialogic teaching was found dominant, although there were some indicators of univocal classroom teacher talk. The dialogic discourse allowed the teacher to play roles as initiator and secondary knower, thus influencing the quality of teaching and learning.

The present study focuses on documenting classroom interaction between the teacher and learners when algebra is taught in a foreign language. I study how interaction regularities in a triadic dialogue mode of interaction and multilingual setting vary as a function of various modes of language use in multilingual classrooms.

\section{Language as resource for meaning-making during trouble spots}

Attention to meaning of language is essential for classroom interaction (Moschkovich, 2008; Khisty \& Chval, 2002). In many countries, the language of instruction in mathematics classrooms is different from the local spoken language due to economic and political reasons. In these countries, students bring with them their home languages. As a result, mathematics teachers are obliged to deal with language diversity during classroom talk. Recent work in sociolinguistics of multilingualism and in mathematics education on multilingual classrooms has stressed the value of perceiving students' linguistic repertoires as resources. Current research discusses the diversity of language use as (re)sources for meaning-making (e.g. Barwell, 2018; Moschkovich, 2008; Planas, 2018, 2021; Planas \& Setati-Phakeng, 2014).

Regarding the conceptualization of language as a resource for meaning-making, Moschkovich's (2008) examines students' ability to draw on resources from everyday experiences as well as resources from the classroom such as gestures and drawings. Planas and Setati-Phakeng (2014) refer to language simultaneously as a problem, as a right and as a resource, with emphasis on the latter perspective. Here, home language can be seen as a right in multilingual mathematics teaching and learning, while learning mathematics in a foreign language can be seen as a problem. Tensions can thus appear 
along teachers' attempts to manage both teaching mathematics and teaching the language of instruction (Planas \& Setati-Phakeng, 2014). Mathematics education researchers with a focus on multilingual issues hold a similar view, namely, that language as a resource for the development of meaning-making goes with tensions between languages (Planas, 2018). Exploring tensions in multilingual mathematics classrooms was initiated by Adler's key work on dilemmas (2001). Adler refers to three dilemmas (code-switching, transparency and mediation) as a resource for making meaning in multilingual classrooms. She argues that these dilemmas "lie at the heart of teaching and learning secondary level mathematics in multilingual classrooms” (p. 1).

Studies on multilingual mathematics classrooms in various parts of the world like South Africa (Adler, 2021), Catalonia, Spain (Planas, 2018), Malta (Farrugia, 2009), or California, United States (Moschkovich, 2008) illustrate the value of language as resource for meaning-making. They show teachers and learners using their spoken language and the language of instruction to engage meaningfully in classroom interaction. Code-switching, or multilinguals moving between languages during a conversation or at the level of an utterance (Farrugia, 2009), is valued as a strategic resource for meaning-making and to deal with challenges resulting from using various languages. Adler (2001) and El Mouhayar (2021) report teachers resorting to codeswitching as a skillful and deliberate mode of instruction. It is shown teacher's codeswitching to provide feedback in order to make content accessible to students, to refer to mathematical technical terms; or to connect language and other representations.

\section{Design of the research and methods}

This research studies classroom talk when early algebra is taught in a foreign language in the middle school. My guiding question is: How does language use in teacher talk vary during trouble-spots in early algebra-specific multilingual classrooms? Even though I take Vygotsky's sociocultural approach as key, I acknowledge the dialogic nature of interaction, and refer to language as resource for learner meaningmaking. I place the spot light on the teacher's utterances because of their fundamental role in classroom interaction. With this focus, I align with research in mathematics education on teacher talk, teaching and language in classrooms (Adler, 2021; Planas, 2021). Overall, the focus herein is on the role of teacher talk in the multilingual mathematics classroom, particularly in the interaction between teacher and learners during trouble-spots. I explore regularities in classroom teacher talk of two grade seven classrooms and compare those regularities in terms of language use.

The study was conducted in Lebanon, where most private and public schools follow the national mathematics curriculum that is content-oriented with algebra as a major topic. The data for the study comes from two grade seven mathematics classrooms - one in a public school (Nour's class), in which French is the language of instruction and the other (Elie's class) in a moderately sized private school, in which English is the language of instruction. Both schools are located in a suburb in the greater Beirut area serving middle to low socio-economic background students as reflected in the schools' achievement levels. Eighteen sessions in grade seven in the two schools were video-andaudio taped, ten of which occurred in the private school. Videotapes were transcribed verbatim and transcriptions were coded based on Wells (1999) to monitor sequential features of classroom discourse interaction. According with Amin and Badreddine (2020) where exchange is the central feature, the least possible unit of spoken discourse interaction between speakers was preserved, which involved initiation and response moves. An exchange may also entail a follow-up move, in which the speaker may 
reformulate, repeat or justify a response. Sequences constitute levels broader than an exchange. A sequence enables perceiving interaction as a chain of exchanges of two types, nuclear and dependent. In a nuclear exchange, a novel topic is inserted. This type has a specific extent of independence from preceding exchanges and can be selfcontained. A dependent exchange is a type that does not stand by itself since it depends on the presence of a preceding nuclear exchange.

Coding was done at the levels of exchange type (nuclear, dependent) and of sequence. I aimed at getting a picture regarding the development of interaction in a classroom and identifying trouble-spots. The analysis was done qualitatively and quantitatively to capture various ways in which interaction evolved during trouble-spotsequences (TSS) and the modes of language use during those TSS. Initiation, response and follow-up are distinguishable moves within an exchange. Each of those moves correspond to one utterance and every utterance was also coded with respect to the function it serves (Amin \& Badreddine, 2020; Wells, 1999). So, every utterance was coded for the classroom in which it occurred (Elie or Nour's) and the interlocutor (teacher or student). Moreover, each utterance was coded based on the language used. As a result, three modes of language use within an utterance emerged: (1) English-only or French-only; (2) Arabic-only; and (3) mixed languages whenever there is a mix of Arabic and English or French. To establish reliability in coding, a team of four research assistants coded the data under my guidance. The interrater reliability between coders during a final stage of coding was more than $80 \%$. This score was used to establish reliability in coding exchange type, sequence, trouble-spot, move, function and utterance type. 8966 utterances out of 11122 utterances were finally considered. Those utterances contributed to classroom interaction during TSS.

\section{Selection of findings}

I now focus on identifying commonalities and discrepancies that exist during TSS between the two classrooms, in terms of language use, moves and functions. While quantitative analysis shows regularities within each classroom as well as similarities and contrast differences in language use, qualitative analysis serves to select representative excerpts around the guiding question stated for the study.

\subsection{Comparing the language of instruction and home language}

Interaction in the two classrooms mainly followed the triadic dialogue structure with teacher initiation, student response and teacher follow-up moves. This section starts with a description of the language of instruction and colloquial Arabic by the teachers during TSS as they taught algebra. I then report dominant discourse regularities and compare commonalities and discrepancies.

Table 1 shows the percentage use of the language of instruction (English or French) or the home language (colloquial Arabic) during TSS, either separately or mixed within an utterance. Elie's home-language mixed with English is reflected in his greater utilization of code-mixing (56.1\%) compared to his utilization of English only (31.7\%). Nour's French only is reflected in her greater utilization of language of instruction $(61.8 \%)$. Moreover, learners in Elie's class utilized mixed-languages with a larger percent $-37.6 \%$ of the utterances- than learners in Nour's class who only utilized codemixing in $14.7 \%$ of utterances. In contrast, the degree of learners' participation in the two classrooms is similar. Learners in Elie's class contribute $35.3 \%$ of the utterances compared to $38.4 \%$ in the case of Nour's class. 
Table 1. Cross-tabulation of language use by interlocutor and by classroom during TSS

\begin{tabular}{|c|c|c|c|c|c|c|c|c|c|c|}
\hline \multirow[b]{3}{*}{ Classroom } & & \multicolumn{8}{|c|}{ Diversity in language use } & \multirow[b]{2}{*}{ Total } \\
\hline & & \multicolumn{2}{|c|}{$\begin{array}{c}\text { Foreign } \\
\text { instructional } \\
\text { language } \\
\end{array}$} & \multicolumn{2}{|c|}{$\begin{array}{c}\text { Colloquial } \\
\text { Arabic } \\
\end{array}$} & \multicolumn{2}{|c|}{$\begin{array}{r}\text { Mixed } \\
\text { languages } \\
\end{array}$} & \multicolumn{2}{|c|}{ Other* } & \\
\hline & & Freq. & $\%$ & Freq. & $\%$ & Freq. & $\%$ & Freq. & $\%$ & Freq. $\%$ \\
\hline \multirow[t]{3}{*}{ Elie } & Teacher & 548 & 30.7 & 158 & 8.9 & 1073 & 60.1 & 5 & 0.3 & 1784100 \\
\hline & Learner & 458 & 46.5 & 117 & 11.9 & 373 & 37.9 & 37 & 3.8 & $985 \quad 100$ \\
\hline & Total & 1006 & 36.3 & 275 & 9.9 & 1446 & 52.2 & 42 & 1.5 & 2769100 \\
\hline \multirow[t]{3}{*}{ Nour } & Teacher & 2428 & 62.1 & 545 & 13.9 & 936 & 23.9 & 0 & 0 & 3909100 \\
\hline & Learner & 1696 & 74.1 & 230 & 10.1 & 361 & 15.8 & 1 & 0 & 2288100 \\
\hline & Total & 4124 & 66.5 & 775 & 12.5 & 1297 & 20.9 & 1 & 0 & 6197100 \\
\hline \multirow[t]{3}{*}{ Total } & Teacher & 2976 & 52.3 & 703 & 12.3 & 2009 & 35.3 & 5 & 0 & 5693100 \\
\hline & Learner & 2154 & 65.8 & 347 & 10.6 & 734 & 22.4 & 38 & 1.2 & 3273100 \\
\hline & Total & 5130 & 57.2 & 1050 & 11.7 & 2743 & 30.6 & 43 & 0.5 & 8966100 \\
\hline
\end{tabular}

* Other category corresponds to gestures such as nodding or writing

\subsection{Illustrations of distinguished interaction routines and language use}

While findings show a larger extent of home language during TSS in Elie's class, Nour and learners utilize French to a larger extent. The excerpts below, showing dominant discourse patterns and trends of interaction from each class, illustrate those discrepancies during TSS. The first excerpt shows continual use of mixed languages, including home language and English in Elie's class during TSS. This excerpt involves classroom teacher talk of the "flock of birds" pattern (Figure 1), in which Elie uses the figure of the arranged flock of birds on day one to discuss with learners a formula to determine a relation between number of days and total number of birds.

During winter, birds migrate towards countries where the weather is warmer. These birds fly in the form of a V-shape. On the first day only three birds were flying. Every day, two birds join the flock while maintaining the $\mathrm{V}$-shape. The figure below shows the number of birds flying on the first day.

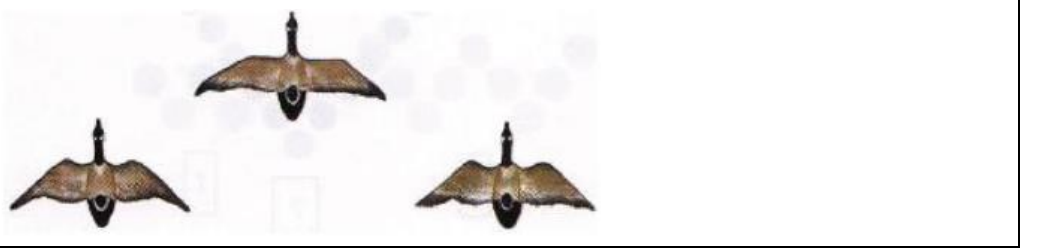

Figure 1. Flock of birds

The representative sequence illustrates characteristics that are common in the discourse pattern in Elie's class. It first shows strict triadic dialogue in which the initiation and follow-up moves are performed by Elie whereas the responses are contributed by leaners. It then shows continuous use of mixed-languages (colloquial Arabic and English) by Elie and learners. Bold words denote Lebanese Arabic whereas bold and italicized words denote translation of Arabic to English.

\begin{tabular}{llllll}
\hline 1 & Teacher & Question number two: let D be & Initiate & Read & Nuclear \\
& the number of days...day & & & \\
& $\begin{array}{l}\text { number. And let B be the total } \\
\text { number of birds. }\end{array}$ & & &
\end{tabular}


طلعوا بشي

come up with a formula between

$\mathrm{B}$ number the birds and $\mathrm{D}$ the

day number.

Maggie ب طلع came up with a

formula for birds joining the

flock.

لـ for the formula

نحن بدنا

we want the total number of

birds

$$
\text { هول كيف عم يتغيروا? }
$$

Those, how are they changing?

What's the pattern between these figures? Rayan and Ali

2 Rayan: We take the number of birds joining the flock and the total number of birds....

3 Teacher بدنا

: we want formula for the total number of birds

$$
\text { شو ال formula يللي طلعتوا فيها؟ }
$$

What is the formula that you came up with?

4 Rayan:

منعل we do five minus two equal three

5 Teacher

Five minus two equal three

6 Rayan:

Five minus two gives three which is the constant number of the birds.

7 Teacher الول شي 1 first thing the formula then you explain to me. What's your formula? The formula متل هاي لازم يكون فيها should contain such as those B and D.

8 Rayan: Birds joining the flock minus the total number of the birds.

9 Teacher ارجعي عيدي repeat again

10 Rayan: Birds joining the flock minus the total number of the birds.

11 Teacher Total number of birds يعن means B شنتي منها you took from it the birds joining the flock and then what did you do with the response?

12 Rayan:

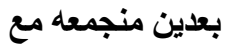

then we add it with birds joining the flock.

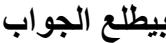

Request action

Acknowledge

Clarify

Request suggest

Nominate

Respond Suggest

Follow-up Clarify

Initiate Request suggest Dependent Exchange

Respond Suggest

Follow-up Repetition

Respond Clarify

Follow-up Request suggest Clarify

Respond Suggest

Follow-up Request repeat

Respond Repetition

Follow-up Clarify

Request suggest

Respond Suggest

Inform 
13 Teacher $:$

14 Teacher

$$
\text { : }
$$

the result will be obtained for the total number of birds the result will be obtained for the total number of birds? Okay.

$$
\begin{aligned}
& \text { فيكم تقولولي، قبل ما نجربها، شو يللي ما }
\end{aligned}
$$

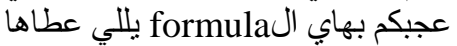

$$
\begin{aligned}
& \text { هال هroup } \\
& \text { as a first قبل ما نجرب، شو في شي }
\end{aligned}
$$

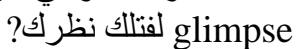

$$
\begin{aligned}
& \text { في شي ما استعملوه؟ }
\end{aligned}
$$

Can you tell me, before we try it, what you did not like in this formula that this group has suggested. Before we try, what is there as a first glimpse that captured your attention? Fadel

15 Fadel: D

16 Teacher The day number. Their formula is independent of, مستقلة عن independent of, the day number. for them the day number is not essential.

let us try. even though بالرغم من انه ما في there is no day number. أي which number should I select?

لاحظتوا المشكلة يللي عم نوقع فيها did you notice the problem that we are facing?

ون ون بنقي and I try it but here there is no day number حتى جريها، in order to try

I أبي جرياه which day number have to try?

17 Rayan: Any day.

18 Teacher Any day? Day five لازم يطلع should be eleven birds Okay. The total number of birds B equal to $\mathrm{B}$.

in order to get the total number of birds لازم اعرف I

should know the total number of birds?!

شفتوا وين المشكلة يللي عم نوقع

فيها we are facing? Total number of birds is total number of birds.

19 Teacher
Follow-up Request confirm Acknowledge

Initiate

Request

Dependent evaluate

Exchange

Request inform

Evaluate reject
Nominate

Respond Inform

Follow-up Inform

Evaluate reject

Clarify

Respond Justify

Follow-up Request confirm

Clarify

Inform
Initiate

Check

Dependent

Request inform Exchange 
Did you understand where the

problem is? Please, help us

وين عم بتلاقي مشكلة

Where are you facing a problem

in applying this formula?

وين في

where is there another problem

غير other than this B equal to B

هاي

Jerald

20 Jerald: كيف فينا نعرف ال

how can we know the

total number of birds

اذا ما منعرف شو هني

if we do not know what they

are?

21 Teacher

Okay. What about the birds كيف بلي اعرف مuت

قدي how can I know how much

is the number of birds joining the

flock? On day twenty-five for example, كيف بدي اعزف how can I

know how many birds joined the flock on day twenty-five? There are so many problems with your formula, but at least you tried. That's okay.

22 Teacher Write it and explain by words

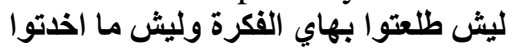
why did you come up with this idea and why you did not take into consideration day number? There should be a reason for that. Okay?
Request inform

Nominate
Respond Inform

Follow-up Acknowledge

Inform

Evaluate reject

Initiate Request justify

Figure 2. Excerpt from Elie's class TSS with mixed-language and triadic dialogue

The excerpt contains four turns of the teacher utilizing the "request inform" or "request suggest" functions in the initiate move (turns 1, 14, 16 and 18). Contrary to asking for information, there is more than one possible correct response to the "request suggest". When the teacher requests a suggestion, more than one response would be adequate. He requests a suggestion from a number of possible ways in finding a relation between day number and the number of birds (e.g. turn 3) or in seeing variants (e.g. turn 1). Another feature more typical of Elie's class is the nominate function. Three turns of the teacher show the nominate function in the initiate move (turns 1, 13 and 18). This use of nominate illustrates how Elie controls the interaction and the contribution of the learners by selecting who is going to respond to his questions.

This TSS also illustrates features more typical in Elie's follow-up moves. It reveals five instances of the clarify function in the follow-up move (turns 3, 7,11, 16 and 18). Clarification in the follow-up move depicts Elie's focus on mixed languages as a resource for meaning-making. In turn 16, Elie rephrases Fadel's brief response (D in turn 15) using mixed languages with English for technical language "day number" and colloquial Arabic for deictic function " هون (here)" and reference to students "بالنسبة الهم 
(for them)". The excerpt contains two turns of request confirmation function (turns 13 and 18) and one turn for requesting information in the follow-up moves (turn 18).

More typical of Elie's class are also teacher's conceptual and procedural-inquiry utterances. While conceptual utterances involve learners in making connections that enable them to function together within the larger structure, procedural inquiry utterances address how to do something such as processes of inquiry (e.g. observe, compare) (El Mouhayar, 2020a). Elie involves learners in determining a formula that associates the number of birds with the day number. He infuses conceptual utterances about this relation in turns 1,14, 16 and 19. The dominance of conceptual talk could be designated to the nature of discourse, which involves determining a relation between day number, total number of birds and number of birds joining each day.

A fourth feature of Elie's class is that utterances of learners' responses are brief, limited to a few words or short statements. Elie and learners use mixed languages in almost all utterances in the TSS for various functions. They use colloquial Arabic to refer to: (1) demonstratives such as "هول [those]" (turn 1), and deictics such as "ول شي [first thing]" (turn 7) to address specific issues in dealing with the formula; (2) interconnectivity means including copular verbs such as "طلعوا بشي "came up with] (turns 1, 7 and 8); (3) conjunctions such as "ل [for]" (turn 1), "ال [the]" (turn 7), and "بعدين [then]" (turn 7). They also use colloquial Arabic to refer to personal voices. This is illustrated by teacher's utterances (turn 3) such as "بدنا [we want]" and students" utterances such as "منعمل" [we do] (turn 4). Elie uses English to refer to technical words like "total number of birds" or "number of days" or "formula" (turn 7).

The excerpt from Nour's class differs from Elie's in terms of functions related to interaction moves, language, utterance knowledge type and mathematical lesson. The excerpt corresponds to a lesson dealing with algebraic expressions with a focus on reducing, simplifying, developing, and factorizing algebraic expressions. Teacher and learners are discussing what to do with the expression $5 x+3$. This excerpt shows dominant use of French and strict triadic dialogue where teacher's moves mainly contribute to initiation and follow-up moves. Bold words denote Lebanese Arabic whereas bold and italicized words denote translation of Arabic to English. Non-bold but italicized words denote translation of French to English.

1 Teacher:

Students:

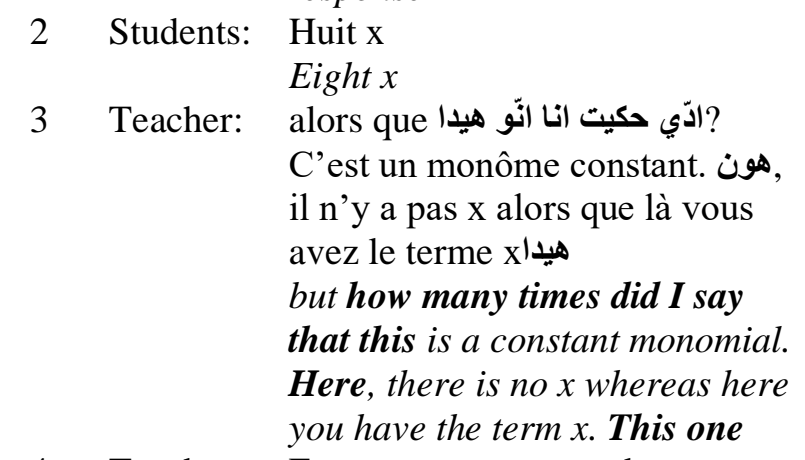

4 Teacher:
Si j'ai cinq x plus trois و قطنالكن de choisir la réponse

If I have five $x$ plus three and we

told you to determine the

response

Eight $x$

C'est un monôme constant. هون أنابن

Cه

Est-ce que ceux sont deux

monômes semblables?

Are those two similar

monomials?
Request inform Initiate

Nuclear

Exchange

$\begin{array}{ll}\text { Inform } & \text { Response } \\ \text { Inform } & \text { Follow- } \\ & \text { up }\end{array}$

$\begin{array}{lll}\text { Request } & \text { Initiate } & \text { Dependen } \\ \text { pos/neg } & & \mathrm{t} \\ & & \text { Exchange }\end{array}$ 
6 Teacher: Non, ils n'ont pas la même partie

Reformulate Followlittérale, ici, je ne peux pas les

Extend up additionner No, they do not have the same literal part, here, I cannot add them.

7 Joe: Madame

Bid

Initiate

Dependen Miss

Nominates

Response

8 Teacher: إيه

9 Joe:

Yeah

Suggest

Initiate plus cinq Five $x$ plus three we do three $x$ plus five

10 Teacher: Ahh. انتبهو شوي. Trois x plus

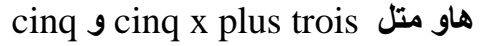
بعضن

Request action Initiate Reformulate

Request

pos/neg

Ahh. Pay attention. Three $x$ plus five and five $x$ plus three. Are those similar?

11 Students: Non

No

Pos/neg Response

12 Teacher: Trois x متل cinq x Joe?

Request Is three $x$ similar to five $x$ oh Joe

pos/neg

Initiate

$\mathrm{t}$

Exchange

Non

Pos/neg

Response

No

14 Teacher: J cinq J S trois ? Is the five similar to the three?

Request

Initiate

pos/neg

Dependen

Pos/neg

Exchange

15 Students: لأ

No

Response

16 Teacher: Trois x plus cinq cinq plus trois x, بسّ مش متل cinq x plus

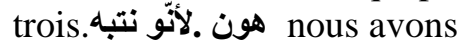
trois x. Quel est le terme qui contient $\mathrm{x}$ ici?

Three $x$ plus five is similar to five plus three $x$, but not similar to five $x$ plus three. Because pay attention. Here we have three $x$.

Inform Initiate

Dependen $\mathrm{t}$

Exchange

Request inform

Dependen Exchange What is the term that contains $x$ here?

17 Students: Trois Three

18 Teacher: Trois

Three

19 Teacher: Que veut dire 3x? What does three $x$ mean?

20 Etian: $\quad X$ fois $x$ fois $x$ $X$ times $x$ times $x$

Inform Response

Repetition

Follow-

up

Request inform Initiate

Inform

Response
Dependen $\mathrm{t}$

Exchange 
21 Teacher: Trois $\mathrm{x}$ n'est pas $\mathrm{x}$ fois $\mathrm{x}$ fois $\mathrm{x}$ لأ.

No. three $x$ is not $x$ times $x$ times $x$

Trois x c'est $\mathrm{x}$ plus $\mathrm{x}$ plus $\mathrm{x}$.

C'est la somme de $\mathrm{x}$

Three $x$ is $x$ plus $x$ plus $x$. It is the sum of $x$

22 Etian: Plus?

Plus?

23 Teacher: إيه. C'est x plus

Yes. It is $x$ plus

24 Teacher: Quel est le coefficient?

What is the coefficient?

Ceux ne sont pas ici des

monômes semblables يtian?

Are those similar monomials oh

Etian

Quel est le coefficient ici?

What is the coefficient in here?

25 Students: Un

One

26 Teacher: Un et un et un

One and one and one

27 Teacher: Comment? qu'est-ce que

j'additionne?

How? What do I add?

Les coefficients c'est-à-dire c'est

égal à un plus un plus un facteur

de $\mathrm{x}$. Alors que $\mathrm{x}$ fois $\mathrm{x}$ fois $\mathrm{x}$,

vous avez ici comme exposant

ادّي C'est x à la puissance?

The coefficients, this means it is

equal to one plus one plus one as

a factor of $x$. Whereas $x$ times $x$

times $x$, you have in here the

exponent, what is its value? It is

$x$ to the power?

28 Student: Trois

Three

29 Teacher: Trois

Three

Donc x à la puissance trois est le produit de $\mathrm{x}$ trois fois par luimême alors que trois x c'est la somme de $\mathrm{x}$ trois fois,

n'est-ce-pas?

So $x$ to the power three is the product of $x$ three times by itself whereas three $x$ is the sum of $x$ three times, right?

30 Students: Oui

Yes

31 Teacher: D'accord?

Okay?
Evaluate reject Follow-

up

Reformulate

Request

Initiate

Dependen

confirm

$\mathrm{t}$

Pos/neg

Reformulate

Response Exchange

Request inform Initiate

Dependen

Request Pos/neg

$\mathrm{t}$

Nominate

Exchange

Request inform

Inform Response

Inform

Follow-

up

Request inform Initiate

Dependen

$\mathrm{t}$

Inform

Exchange
Inform Response

Repetition

Follow-

Reformulate

Request

pos/neg

up
Pos/neg Response

Check

Initiate 


\begin{tabular}{llllll}
32 & Students: & Oui & Pos/neg & Response & \\
& Yes & & Dependen \\
& & & \\
& & & \\
Bon & Teacher: & Good & Evaluate accept & Follow- \\
up & Exchange \\
\hline
\end{tabular}

Figure 3. Excerpt from Nour's class TSS with dominant French and triadic dialogue

First, the excerpt reveals several initiate move utterances in which Nour requests factual information (turns 1, 16, 19, 24 and 27). Contrary to the request suggest function, the request information involves asking a question regarding a specific topic for which only one specific response is possible. This response can either be correct or incorrect. In turn 16, the teacher asks, "Here we have three $\mathrm{x}$. What is the term that contains $\mathrm{x}$ here?" The correct response was said by a student "three" (turn 17). The TSS also contains an initiate move where Nour provides factual information (turns 16 and 27) with basic elements that learners must know to manipulate algebraic expressions or to solve the problem. "Three $\mathrm{x}$ plus five is similar to five plus three $\mathrm{x}$, but not similar to five x plus three" (turn 16) shows factual information that learners must know to deal with algebraic expressions. Asking for a yes or no response appears several times in the initiate moves of the teacher (turns 4, 12, and 14) even though this function is not among the first six dominant functions in Nour's moves.

The excerpt also illustrates features more typical in Nour's follow-up moves. It contains two instances of offering information (turns 3 and 26), and two of repeating a learner's response (turns 18 and 29). Another feature more typical of Nour's class are teacher's extensive factual and procedural-algorithmic utterances. While Nour's factual utterances involve basic elements that learners must know to manipulate the algebraic expression, procedural-algorithmic utterances address how to use and apply formulas and procedures related to algebraic expressions. In this TSS Nour involves the learners to compare how to carry out the multiplication of $\mathrm{x}$ three times and sum of three $\mathrm{x}$, "So $\mathrm{x}$ to the power three is the product of $\mathrm{x}$ three times by itself whereas three $\mathrm{x}$ is the sum of $x$ three times" (turn 30). As a result, Nour infuses factual utterances (e.g. turns 1, 16, 19, 24 and 27) and procedural-algorithmic utterances (e.g. turn 30). Similarly, learners' utterances are at the factual level (e.g. turns 3, 13, and 17, 25 and 28). The dominance of procedural and factual talk could be designated to the nature of the discourse, which involves carrying out various operations on algebraic expressions.

The mixing of language of instruction and colloquial Arabic in Nour's class is very different to that in Elie's. This TSS illustrates this distinction regarding the functions associated to interaction moves and characteristics of language use. What is noteworthy is that Nour rarely uses colloquial Arabic and learners stick to using the language of instruction. Additionally, reference to Arabic is limited to one to two words within an utterance. It is very rare that the teacher refers to more than two Arabic words within an utterance (e.g. turns 3, 10 and 16). The majority of colloquial Arabic words play a role in managing the flow and structure of the discourse. However, those terms do not make a change to the mathematical meaning related to the discourse in the sequence. The teacher uses colloquial Arabic for the purposes of connectivity including copular verbs

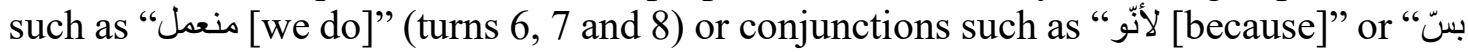
[but]" in (turn 16) "و [and]" (turns 1 and 10), "then" (turn 8) and "J [the]" (turn 14). In turn 16 Nour uses "but" to introduce a new statement "but not similar to five $\mathrm{x}$ plus three" that adds to, "three $\mathrm{x}$ plus five is similar to five plus three $\mathrm{x}$ " and contrasts with it in some way. Some colloquial Arabic words play the role of discourse markers such as " إيه" [yeah]" (turn 8) and" (turns 12 and 24) to nominate a student. Nour also uses colloquial Arabic words to refer to deictic functions such as "هون [فيدا" [there], 
(turn 3) " هاو [those]" (turn 10) to refer to parts of the algebraic expression on the board. So, deictics are used to focus attention on specific objects of the algebraic expression on the board accompanied by hand pointing. Colloquial Arabic is used to refer to pronouns

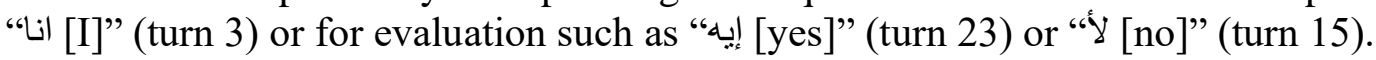

To sum up, Elie's greater utilization of colloquial Arabic is associated with a greater focus to involve learners in higher level reasoning (conceptual and procedural-inquiry knowledge types). In contrast to Nour, Elie consistently and frequently utilizes home language, which play various roles in the process of generalization. Elie is more likely to use colloquial Arabic to refer to (1) deictic means; (2) adverbs of generative action; (3) pronouns; (4) calling out numbers and operations; (5) copular verbs in addition to other usage such as affirmation, negation, and request for justification or to request other strategies or for management. Those linguistic terms are associated with the content of the mathematical topic or discourse. Nour, on the other hand, involves learners in lower level reasoning (factual and procedural-algorithmic knowledge types) in alignment with the tasks in the textbook. Nour's colloquial Arabic can be considered as limited to managing the flow of the discourse. Nevertheless, the TSS in this study were selected to illustrate contrast and to emphasize discrepancies that were highlighted in the quantitative analysis. There are large differences that exist within each of the two classrooms. In the next section I discuss findings with an emphasis on their implications in relation to the question of how colloquial Arabic influence classroom teacher talk during the teaching of algebra in the middle school.

\section{Discussion}

This study has investigated the association of language use and patterns of interaction between teacher and learners during trouble-spots in two grade seven multilingual classrooms. I now further discuss the findings in the light of the theories undertaken. By adopting ethnomethodology, I focused my analysis on the interactions between learners and teacher and on what they utter and how to state their utterances. This allowed me to examine classroom interaction complexity and to focus on characterizing structures and regularities of interaction in teaching algebra and during multilingual trouble-spots. Overall, triadic dialogue was found in both classrooms, with function that were content oriented. Nevertheless, conceptual and procedural-inquiry knowledge types characterized the discourse elicited in Elie's class, whereas factual and procedural-algorithmic knowledge were dominant features of discourse in Nour's class. In his follow-up moves, Elie intended to scaffold learners' reasoning with mixed languages (colloquial Arabic and English). Nour showed more interest in content with low-level reasoning. Her follow-up moves were more likely to repeat a learner's response or to request factual information. This was associated with limited colloquial Arabic for discourse markers. It can thus be concluded that the quality of discourse in Nour's class resembles Wertsch's (1991) univocal discourse. In contrast, the quality of discourse in Elie's class resembles Wertsch's dialogic discourse.

While the study is limited to two classrooms and the lessons are content-specific, systematic and comparative analyses of interaction, and the choice to adopt the view of languages as being distinct with a focus on teacher talk, show home language as a resource for mathematical meaning-making. Language in classroom teacher talk was coded at broad levels to classify categories that are not content specific even though the illustrations analyzed are content specific. As such, this study adds to mathematics education literature on exploring content-specific language in classroom teacher talk with the aim to begin to see the general (e.g. Adler, 2021; Planas, 2021). 
The practices in both classrooms indicate that the two teachers view language as a resource. The analyses reveal code-mixing and colloquial Arabic as natural move between languages during teacher talk. Moves between colloquial Arabic and English or French during classroom interaction created a notable aspect of discourse that helped to involve learners in learning. While it can be concluded that participants in both classrooms perceive language as a resource, it is unclear whether the value of this resource is similar. Quantitative analysis shows that Elie refers to colloquial Arabic more frequently than learners. This may be due to the higher frequency of teacher's utterances during TSS. Reference to colloquial Arabic was accompanied with codemixing, with one or more words borrowed from English and embedded into teacher's or learner's utterance. Elie code-mixes and while doing so, he refers to technical terms in English such as "figure" or "squares". This may be due to rare use of those terms in colloquial Arabic in every day experience. By using those terms in English, the teacher aims that learners understand and employ those mathematical technical terms in English. As for Nour and learners, the use of colloquial Arabic is limited.

Mixed language use in each classroom and how colloquial Arabic and language of instruction were used in teacher talk can be discussed from the conceptualization of language as resource for meaning-making (Planas, 2018, 2021; Barwell, 2018), and from the perspective of seeing language as right or as problem (see Planas \& SetatiPhakeng, 2014). The teacher in the mixed-language dominant classroom made explicit comments about language that can be viewed from language-as-right and language-asproblem perspectives. Elie seems to perceive colloquial Arabic as a right for learners to be able to talk about their mathematical ideas, and seems to recognize English as a problem. He encourages learners to use Arabic, "In Arabic if you want. Don't worry about English. You have to speak up. We can barely hear your voice" (session 1, turn 146). In contrast, Nour seems to think that learners have the right to learn to use French in mathematics and she seems not to consider French as a problem. This is manifested in the dominant use of French in her class interaction.

More research is certainly needed in multilingual mathematics classrooms to reinforce the current findings, to analyse other features of the role of colloquial Arabic in teaching and learning algebra, and to enhance methodological tools. There is a lot of research to be done in the Arab world and other multilingual countries in order to understand the profits and challenges of teaching mathematics in a foreign language, particularly for learners from low or middle socioeconomic status.

\section{Acknowledgement}

This study is funded by AUB Funds; 14110 Office of the Provost; 11190 Education (Award No. 102725; Project No. 21068; grant holder R. El Mouhayar).

\section{References}

Adler, J. (1999). The dilemma of transparency: Seeing and seeing through talk in the mathematics classroom. Journal for Research in Mathematics Education, 30(1), 4764.

Adler, J. (2001). Teaching mathematics in multilingual classrooms. Dordrecht, Netherlands: Kluwer Academic Publishers.

Adler, J. (2021). Content and context specificity matter in the 'how' of languageresponsive mathematics teacher professional development. In N. Planas, C. Morgan, 
\& M. Schütte (Eds.), Classroom research on mathematics and language: Seeing learners and teachers differently (pp. 77-100). London, England: Routledge.

Alibali, M. W., Nathan, M. J., Church, R. B., Wolfgram, M. S., Kim, S., \& Knuth, E. J. (2013). Teachers' gestures and speech in mathematics lessons: Forging common ground by resolving trouble spots. ZDM-Mathematics Education, 45(3), 425-440.

Amin, T., \& Badreddine, D. (2020). Teaching science in Arabic: Diglossia and discourse patterns in the elementary classroom. International Journal of Science Education, 42(14), 2290-2330.

Bakhtin, M. M. (1981). Discourse in the novel. In M. M. Bakhtin (Ed.), The dialogic imagination: Four essays (pp. 259-422). Austin, TX: University of Texas Press.

Barwell, R. (2018). From language as a resource to sources of meaning in multilingual mathematics classrooms. The Journal of Mathematical Behavior, 50, 155-168.

El Mouhayar, R. (2019). Triadic dialogue during classroom talk in the context of pattern generalization. In M. Graven, H. Venkat, A. Essien, \& P. Vale (Eds.), Proceedings of the 43rd Conference of the International Group for the Psychology of Mathematics Education (Vol. 2, pp. 224-231). Pretoria, South Africa: PME

El Mouhayar, R. (2020a). Investigating quality of class talk in grade 7: The case of pattern generalization. International Journal of Science and Mathematics Education, DOI: 10.1007/s10763-020-10092-8

El Mouhayar, R. (2020b). Triadic dialogue in multilingual mathematics classrooms as a promoter of generalization during class talk. Mathematics Education Research Journal, DOI: 10.1007/s13394-020-00325-y

El Mouhayar, R. (2021). The role of languages in the process of objectification in pattern generalization in a multilingual mathematics classroom. International Journal of Science and Mathematics Education, DOI: 10.1007/s10763-021-10174-1

Farrugia, M. T. (2009). Reflections on a medium of instruction policy for mathematics in Malta. In R. Barwell (Ed.), Multilingualism in mathematics classrooms (pp. 97112). Clevedon, England: Multilingual Matters.

Garfinkel, H. (1967). Studies in ethnomethodology. Englewood Cliffs, NJ: PrenticeHall.

Ingram, J. (2018). Moving forward with ethnomethodological approaches to analysing mathematics classroom interactions. ZDM-Mathematics Education, 50(6), 10651075.

Khisty, L. L., \& Chval, K. B. (2002). Pedagogic discourse and equity in mathematics: When teachers' talk matters. Mathematics Education Research Journal, 14(3), 154168.

Lemke, J. L. (1990). Talking science: Language, learning, and values. Norwood, MA: Ablex.

Moschkovich, J. N. (2008). "I went by twos, he went by one": Multiple interpretations of inscriptions as resources for mathematical discussions. The Journal of the Learning Sciences, 17(4), 551-587.

Planas, N. (2018). Language as resource: A key notion for understanding the complexity of mathematics learning. Educational Studies in Mathematics, 98(3), 215-229. 
Planas, N. (2021). How specific can language as resource become for the teaching of algebraic concepts? ZDM-Mathematics Education, 53(2), 277-288.

Planas, N., \& Setati-Phakeng, M. (2014). On the process of gaining language as a resource in mathematics education. ZDM-Mathematics Education, 46(6), 883-893.

Salloum, S., \& BouJaoude, S. (2019). The use of triadic dialogue in the science classroom: A teacher negotiating conceptual learning with teaching to the test. Research in Science Education, 49(3), 829-857.

Sinclair, J. McH., \& Coulthard, M. (1975). Towards an analysis of discourse: The English used by teachers and pupils. London, England: Oxford University Press.

Vygotsky, L. S. (1978). Mind in society: The development of higher psychological processes (M. Cole, V. John-Steiner, S. Scribner, \& E. Souberman, Eds.). Cambridge, MA: Harvard University Press.

Vygotsky, L. S. (1986). Thought and language (A. Kozulin, Ed.). Cambridge, MA: MIT Press.

Wells, G. (1999). Dialogic inquiry: Toward a sociocultural practice and theory of education. Cambridge, MA: Cambridge University Press.

Wertsch, J. V. (1991). Voices of the mind: A sociocultural approach to mediated action. Cambridge, MA: Harvard University Press

\section{Author' contact details}

Rabih El Mouhayar, American University of Beirut (Lebanon). re29@aub.edu.lb 


\title{
Teachers' use of language in multilingual mathematics classrooms during trouble-spots
}

\author{
Rabih El Mouhayar, American University of Beirut
}

Mathematics teaching in a foreign language may lead to discrimination for some learners specifically during trouble-spots that require the construction of shared-understanding. This study explores the association of language use and patterns of interaction between teacher and learners during trouble-spots in two grade seven multilingual classrooms of Lebanon where mathematics is taught in a foreign language. The study compares and contrasts classroom teacher talk for learners from low or middle socioeconomic status. One of the classrooms is located in a public school in which French is the language of instruction, and the other classroom is in a private school in which English is the language of instruction. Eighteen lessons were recorded and transcribed, and utterances of teacher and learners were coded at the levels of: school; session; interlocutor; language use; move and function. Quantitative analysis of interaction and language use and qualitative illustrations of representative sequences are reported in this article. The triadic dialogue as the dominant mode of interaction and the multilingual nature of language were found as unique aspects of classroom teacher talk. Quantitative analysis shows that the teacher in the private school intended to scaffold learners' reasoning with mixed languages (colloquial Arabic and English), whereas the follow-up moves for the teacher in the public school were dominantly associated with French language with limited use of colloquial Arabic. Qualitative illustrations indicate that conceptual and procedural-inquiry knowledge types characterized the discourse elicited in the mixedlanguage dominant classroom, whereas factual and procedural-algorithmic knowledge were dominant features of discourse in the French dominant classroom. Furthermore, the practices in both classrooms indicate that the two teachers view language as a resource. Nevertheless, differences in the roles of language as a resource for meaningmaking were identified. The teacher in the public school was more likely to use colloquial Arabic to manage the flow and structure of the discourse. The teacher in the private school was more likely to use colloquial Arabic to refer to 1) deictic means; 2) adverbs of generative action; 3) pronouns; 4) calling out numbers and operations; 5) copular verbs in addition to other usage such as affirmation, negation, and request for justification or to request other strategies or for management. The findings of this study are discussed within sociocultural and ethnomethodological views of language as a medium to achieve mathematics teaching and learning of algebra. 